\title{
Acute symptomatic neonatal seizures, brain injury and long-term outcome: the role of neuroprotective strategies.
}

\section{Francesco Pisani , Carlo Fusco , Lakshmi Nagarajan \& Carlotta Spagnoli}

To cite this article: Francesco Pisani, Carlo Fusco, Lakshmi Nagarajan \& Carlotta Spagnoli (2020): Acute symptomatic neonatal seizures, brain injury and long-term outcome: the role of neuroprotective strategies., Expert Review of Neurotherapeutics, DOI: $\underline{10.1080 / 14737175.2021 .1848547}$

To link to this article: https://doi.org/10.1080/14737175.2021.1848547

Accepted author version posted online: 11

Nov 2020.

Submit your article to this journal

Џ Article views: 30

Q View related articles 두

View Crossmark data $₫$ 
Publisher: Taylor \& Francis \& Informa UK Limited, trading as Taylor \& Francis Group

Journal: Expert Review of Neurotherapeutics

DOI: $10.1080 / 14737175.2021 .1848547$

\section{Acute symptomatic neonatal seizures, brain injury and long-term} outcome: the role of neuroprotective strategies.

Francesco Pisani ${ }^{1^{*}}$, Carlo Fusco ${ }^{2}$, Lakshmi Nagarajan ${ }^{3}$, Carlotta Spagnoli ${ }^{2}$

1. Child Neuropsychiatric Unit, Medicine and Surgery Department, University of Parma, Italy

2. Child Neurology Unit, Department of Paediatrics, Azienda USL-IRCCS di Reggio Emilia, Reggio Emilia, Italy

3. Department of Neurology, Perth Children's Hospital, University of Western Australia, Perth, Australia

${ }^{*}$ Corresponding author:

Francesco Pisani

Address: Child Neuropsychiatric Unit, Medicine \& Surgery Department, Neuroscience Section, University of Parma, via A. Gramsci, 14, 43123 Parma, Italy Email: francesco.pisani@unipr.it

\section{Abstract}

Introduction: Neonatal seizures are frequent but underdiagnosed manifestations of acute brain dysfunction and an important contributor to unfavorable outcomes.

Etiology and severity of brain injury are the single strongest outcome determinants. 
Areas covered: The authors will discuss the prognostic role of acute symptomatic seizures versus brain injury and the main neuroprotective and neurorestorative strategies for full-term and preterm infants.

Expert opinion: Prolonged acute symptomatic seizures likely contribute to long-term outcomes by independently adding further brain injury to initial insults. Correct timing and dosing of therapeutic interventions, depending on etiology and gestational ages, need careful evaluation. Although promising strategies are under study, the only standard of care is whole-body therapeutic hypothermia in full-term newborns with hypoxic-ischemic encephalopathy.

Keywords: acute symptomatic; antiseizure medications; brain injury; erythropoietin; experimental models; hypothermia; neonatal seizures; neuroprotection; outcome; status epilepticus

\section{Article highlights}

- Acute symptomatic neonatal seizures are associated with worsening longterm outcome.

- The main prognostic factors are etiology and severity of underlying brain injury.

- Experimental and clinical data suggest and independent role of seizures in brain injury, especially if prolonged.

- Whole body therapeutic hypothermia in full term neonates with hypoxicischemic encephalopathy results in improved long-term outcome and reduced seizure burden. 
- Additional neuroprotective and neurorestorative strategies have been proposed to prevent or reduce detrimental secondary changes, with mixed results. 


\section{Introduction}

Epidemiology:

Seizures are the most frequent manifestation of acute brain injury in newborns.

Recent population-based studies documented an incidence of 2.29/1000 live births [1], and the

following risk factors for seizures: at least one complication of pregnancy, at least one neonatal

complication, low Apgar score, need for resuscitation at birth, intraventricular hemorrhage (IVH)

grades II-IV for preterm, and acute hypoxic-ischemic encephalopathy (HIE) for fullterm infants

[2].

Etiologies:

Acute symptomatic seizures are the most frequent cause of neonatal seizures, fullterm

and near-term neonates being mainly affected by hypoxic-ischemic encephalopathy (HIE) or stroke, and very or extremely preterm newborns by intraventricular haemorrhage (IVH) and its complications, or by white matter injury of prematurity. Additional etiologies include acute metabolic derangements and central nervous system infections [3].

Inborn errors of metabolism and genetically-determined neonatal-onset epilepsies require a different management and will not be reviewed here.

Definition of Neonatal Seizures: 
The current definition of neonatal seizures is EEG-based and requires the presence of at least 10 second-long paroxysmal activity with definite beginning and end [4]. From a clinical point of view, various classifications have been provided in the literature [5-8] and there has been a recent proposal for a new classification by the International League Against Epilepsy (ILAE), which has not been published yet. However, diagnosis requires conventional EEG or amplitude-integrated EEG recordings [8-11]. Based on the association of EEG discharges with a clinical component, they are divided into electroclinical or eletrographic-only, while the category of clinical seizures has been discouraged, as clinical recognition of seizures in newborns is prone to a high risk of misdiagnosis [12,13] and clear-cut clinical evidence has demonstrated the need to treat electrographic seizures just as aggressively as electroclinical ones [14,15].

Treatment:

Available guidance on therapy is mainly based on low-levels of evidence and traditionally relies on phenobarbital, phenytoin, benzodiazepines or lidocaine (depending on regional-specific practice), but the use of levetiracetam is emerging, based on low drug-to-drug interactions, linear kinetics, availability of an intravenous formulation, and evidence for a lower risk of neurotoxicity [16], although a randomized controlled study comparing levetiracetam with phenobarbital documented higher effectiveness of the latter [17]. Overall, response rates approximately range between 40 and 60\% [18-21] but considering the self-limiting nature of acute symptomatic seizures and the diagnostic pitfalls, this is obviously affected by study population and study design (ascertainment tools, timing of administration and of evaluation of effectiveness).

Outcomes: 
Although innovations in critical care, such as improvements in parenteral nutrition and non-invasive respiratory support [22], have reduced mortality, the rate of normal outcomes has decreased in some countries, mainly due to the higher percentage of preterm babies. Importantly, legislative differences concerning end of care also need consideration, and can sometimes account for some inconsistencies, as high rates of transition to palliative care can reduce percentages of patients with unfavorable neurological outcomes. For example, in a population-based study, the incidence of epilepsy after neonatal seizures was $15.2 \%$ (16.3\% in patients born at term, and $14.3 \%$ in preterm-born subjects) [23] in keeping with historical data from a review from the same group [24], documenting stable rates in the last 60 years.

Prognostic factors:

The main prognostic factors in acute symptomatic neonatal seizures include: antenatal factors (placental factors including chorioamnionitis), perinatal factors (gestational age, aetiology, severity and patterns of brain injury as expressed by cranial ultrasound and brain magnetic resonance imaging (MRI), Apgar scores, birth weight, neurological examination, abnormal background EEG) [25-27]. Seizure aetiology is among the key players for outcome [26]. Background EEG and electrographic-only seizures have been found as independent predictors of lack of response to phenobarbital in one study [19]; moderately and severely abnormal EEG was confirmed to be associated with poor response in an additional study, which also identified higher mean seizure score and higher degrees of brain MRI injury (white matter, cortex, and watershed regions) to be associated with poor response to phenobarbital [28]. Based on these readily available variables, prediction models have been constructed, which can be performed at the bed-side by combining clinical, EEG and imaging data $[27,29,30]$. 


\section{Body}

A huge body of literature has tried to separate the detrimental effects of seizures per se from those of their underlying etiology.

2.1 Brain injury and pathophysiology of acute seizures

\subsubsection{Neonatal HIE in full-term newborns}

The pathophysiology of brain injury in HIE has been extensively reviewed [31]. In neonatal $\mathrm{HIE}$, progression of clinical signs occurs after a latent period and then resolves within several weeks [32].

This time-line of clinical evolution is determined by the occurrence of secondary energy failure, clinically announced by seizures and other signs of encephalopathy, the third step after the initial asphyxia and the subsequent latent period of 8-24 $\mathrm{h}$ after resuscitation $[33,34]$. This delayed energy failure is determined by the activation of an excito-oxidative cascade. The earliest event is the activation of excitatory glutamate receptors, especially N-methyl-dextro-aspartate (NMDA) receptors (NMDAR), which determine massive membrane depolarization and entry of calcium in neurons, followed by oxidative stress, worsening mitochondrial dysfunction with lactic acidosis and mitochondrial failure, which can end up in either apoptosis or necrosis, depending on the energy supplies to the cell [35-37] and intrinsic factors to the developing brain [38]. a-amino-3-hydroxy-5-methyl-4-isoxazolepropionic acid (AMPA)-type glutamate receptors, also activated, probably contribute to seizure occurrence at this stage [39]. Inflammation (through glial activation) and delayed cell death also additionally worsen brain damage [31].

\subsubsection{Preterm injury to the white matter}

The main predisposing factors to IVH are the immaturity of the vasculature of the germinal matrix and its passivity to systemic blood pressure changes, which are 
typical of preterm newborns. White matter injury can be favored by cerebral oxygenation changes, infection and inflammation, but also by intrinsic vulnerability to oxidative stress under hypoxic-ischemic conditions [40,41], which are in turn favored by immature vascular supply and autoregulation mechanisms $[40,42]$. In the acute phase, injury to the subplate neurons can transiently increase cortical excitability [43], resulting in acute seizures. The ensuing disruption of projection and association fibers and the secondary effects on the cortical plate and its connections to the thalamus are thought to be key determinants for long-term outcomes, especially relating to epilepsy and cognition [44].

\subsection{Interaction between seizures, brain damage and additional detrimental} pre/perinatal factors

Of note, a body of evidence exists, favoring the view that one sub-injurious event (such as gestational or neonatal systemic inflammation, infection, gestational chronic mild maternal stress, and gestational hypoxia) can sensitize the developing brain to second injurious factors (neonatal insults), causing an exacerbated cascade of deleterious effects on the developing brain, including activation of glutamate receptors, cytokines, toll-like receptor pathways, and apoptosis [45].

\subsubsection{Seizure-related variables and seizure burden}

Semiology per se should not be considered as a reliable prognostic indicator, for two main reasons: the frequent co-occurrence of different seizures types in single newborns [46], and its dependence on etiology [47]. However, there is an important point to make: newborns with exclusively subclinical seizures have higher mortality rates [48], probably because of their poorer neurological and general state [49]. Literature data on humans suggest that outcome is a matter of seizure duration, rather than an all-or-nothing effect. Mortality is significantly associated with seizure 
burden, especially status epilepticus [25,48]. A synergistic effect of status epilepticus with the underlying brain disorder in determining epilepsy has been suggested [50] However, status epilepticus independently predicts outcome, even in comparison with recurrent seizures [27] and is an independent risk factor for epilepsy [46]. Refractory seizures are associated with twice the risk of death than those controlled with the initial antiseizure drug loading dose [48]. However, drug-resistance occurs in the most severely affected infants, and status epilepticus is more frequent in critically ill, encephalopathic newborns $[27,49]$. However, this is unlikely to be the whole story, as standardized treatment protocols have been shown to result in better short-term outcomes, with lower maximum phenobarbital concentrations, lower progression to status epilepticus and shorter in-hospital stay [51]. It would be noteworthy to know what the long-term outcomes of these babies will be, because if improved prognosis is confirmed, this would mean that by applying more rigorous protocols we will be able to address the modifiable amount of brain injury possibly directly linked to the effect of ongoing seizures. An independent role for seizures on outcome has been suggested by clinical research. The relative risk for adverse outcome in neonates with perinatal asphyxia was $8.41(4.07-17.39)$ and for neonates with stroke was 4.95 (1.07-23.0) when suffering neonatal seizures compared to newborns with the same types of brain injury but no seizures [52].

Ictal fraction (calculated as the total duration of seizures/duration of the EEG recording $\times$ hour) is also predictive of outcome, when it exceeds 10 minutes [26]. The number of electrographic seizures (none, 1-75, > 75 seizures) correlates with subsequent mortality and morbidity in a cohort of at-risk newborns and newborns with HIE [14]. 
Furthermore, the odds for abnormal outcome increase over nine-fold if seizure burden exceeds 40 minutes and eight-fold if the hourly seizure burden is over 13 minutes/hour, and this is independent from having electrographic seizures, HIE grade or therapeutic hypothermia. Noteworthy, the mere presence or absence of seizures is not associated with outcome [53]. Longer seizure duration is associated with higher 1-year risk of epilepsy in children with arterial ischemic stroke (including newborns), and each 10-minutes increase in seizure burden is associated with a five-fold risk increase, while having more than 10 seizures increases the risk of epilepsy by 30 -fold compared to no seizures [54]. In newborns with HIE, seizure burden also correlates with severity of brain injury [55]. Infants at risk for hypoxicischemic brain injury, after controlling for injury severity on brain MRI, have a worse motor and cognitive outcome if they have seizures, compared to patients with no seizures [56].

Importantly, it must be emphasized that the critical seizure burden for aggravation of brain damage is still unknown [57], and as a result, the definition of status epilepticus in neonates is still controversial and has not changed [58], in spite of these clinical research data.

\subsection{Mechanisms for seizure-induced detrimental effects}

\subsubsection{Clinical data}

How do seizures result in additional brain damage to that provoked by the initial insult to the developing central nervous system? Some lines of research have been delineated, documenting various involved pathogenic pathways.

\subsubsection{Cerebral blood flow (CBF)}

Seizures can induce detrimental cerebrovascular effects [60], especially in preterm babies, lacking cerebral pressure autoregulation [61]. This means that ictal cerebral 
haemodynamic changes passively reflect systemic haemodynamic events, and notably increases in arterial pressure, which can damage the germinal matrix by increasing intracranial pressure $[60,61]$. A secondary effect from muscle contraction is to be excluded, as these changes are documented irrespective of the presence of a clinical correlate to seizures and in mechanically ventilated neonates [60, 62]. Even more importantly, ictal changes in CBF can also occur without systemic pressure fluctuations. [63]

Brain-derived circulating endothelial cells, which were used in animal models as an indicator of cerebral vascular endothelial damage and seizure-induced cerebral blood flow dysregulation, were looked for in a pilot study on infants with either HIE or IVH with documented clinical seizures and were found to be significantly higher than in infants with cerebrovascular insults and subclinical or no seizures. Furthermore, their levels decreased with seizure control [64].

\subsubsection{Lactic acidosis}

Hyperlactacidemia is a measure of hypoxia, and in full-term newborns with HIE persistent lactic acidosis correlates with severity of EEG abnormalities and seizure burden (mean time to normal lactate: 10.0 hours in infants without seizures versus 27.3 hours in infants with seizures) [65].

Seizures can contribute to lactic acidosis in infants with HIE progressing to severe neurological disability or death [66]. Abnormal lactate levels on spectroscopy in newborns with HIE correlate with neurodevelopmental outcome [67], and in infants with abnormal outcome recovery takes much longer, as the increase is still detectable at 1 month of age [68].

Reliance on anaerobic metabolism has been confirmed by near-infrared spectroscopy (NIRS), which detected a decline in cerebral oxygenation during 
repetitive seizures [62], suggesting an uncoupling between increased metabolic requirements and energy supply [59], resulting in relative cerebral hypoxia [62]. The magnitude of this effect seems to increase in a dose-dependent manner, as each increase in seizure score is independently associated with increased lactate/choline ratio on spectroscopy, even after controlling for confounders [69], demonstrating an independent association of seizure severity with brain injury and wider extent of the hypoxic areas compared to MRI-detectable structural damage [69].

\subsubsection{Animal data}

Animal data offer a heterogeneous landscape of weaknesses and strengths which are unique to the immature brain.

In the secondary phase of hypoxic-ischemic damage, severe seizures can contribute to the spreading of injury from the core to mildly affected regions [70]. Additionally, in animal models of induced cord occlusion, prolonged lactic acidosis is found in those sustaining the most severe cerebral injury on histology [71]. Similarly, in PN1 rats with hypoxic brain injury and prolonged seizures, micro-dialysis performed during seizures detects decreased glucose and adenosine triphosphate, with raised lactate and b-hydroxybutyrate [72], and a marked exacerbation of the extent of cerebral tissue damage. These data are in complete agreement with findings from clinical research in human newborns.

Changes in glutamate and $y$-amino-butyric acid (GABA) receptors have also been reported after status epilepticus in young animals $[73,74]$ and recurrent seizures can adversely affect neurogenesis [75], and induce synaptic reorganization [76-78]. However, compared to older ages, the immature brain shows peculiar characteristics, making it less vulnerable to the excito-toxic effects of glutamate $[79$, 80], probably due to lower calcium entry into the cell, and this resistance may be due 
to smaller density of active synapses, lower energy consumption, and a relative immaturity of cell death cascades.

Interestingly, seizures in the newborn brain are also associated with less oxidative stress than in adults [81]. High concentrations of the mitochondrial uncoupling protein (UCP2), due to the high fat content of maternal milk, also seem to reduce reactive oxygen species (ROS) production in the neonatal brain [82].

However, oxidative stress caused by seizures still represents an important contributor to cerebral vascular injury and cerebral blood flow dysregulation, as documented in a piglet model, in which seizures have been associated with increased ROS in cerebral vessels and cortical astrocytes, contributing to the longterm adverse cerebrovascular effects of seizures [83], although these also show adaptive effects by activating endogenous antioxidant neuroprotective pathways [83]. We discussed some of the main pathways activated by insults to the developing brain and we reviewed the main detrimental effects promoted by seizing activity. What are the main strategies counteracting these cascades? Essentially from a temporal point of view, we can distinguish between neuroprotective and neurorestorative interventions [84] (Figures 1 and 2), which are based on the greater neuroplasticity of the neonatal brain compared to older ages [85].

\section{Neuroprotective strategies}

\subsection{Hypothermia}

Therapeutic hypothermia is the current standard of care for term infants with moderate-to-severe HIE in high-income countries [86]. Newborns receiving standard care plus hypothermia have higher survival without neurological abnormalities, significant reduction in their risk of cerebral palsy or moderate/severe disability [87]. The functional outcome at 7-8 years correlates with the 18-month 
neurodevelopmental assessment, supporting the long-term predictive value of the favorable midterm outcomes reported in the original trials [88]. Based on current evidence, more benefit can be expected in newborns with moderate than severe encephalopathy [89]. Additionally, an even lower incidence of epilepsy at 2 years of age has been reported in comparison with the original randomized controlled trials [90].

If this is exclusively linked to mitigation of brain injury or also positively affected by reduction of seizure-induced damage, it is hard to know. However, a huge body of evidence from animal studies indicates that seizures and epileptiform activity in HIE can be reduced by therapeutic hypothermia [91]. Data on humans have been more conflicting, as reduced incidence and severity of seizures was documented in observational studies but not in meta-analyses of randomized controlled trials [92, 93]. Two observational studies showed lower electrographic seizures burden on continuous EEG in neonates with moderate encephalopathy [94], and after accounting for severity of brain injury on MRI [95], while the third evaluated newborns with arterial ischemic stroke and found lower likelihood of seizures in treated patients compared to neonates with stroke and no hypothermia [96]. The risk of having seizures is lower in cooled than in non-cooled newborns if they have moderate encephalopathy, while no difference was documented between the two groups if the degree of HIE is severe [97]. It is possible that the beneficial effect of hypothermia is insufficient in reversing the excito-toxic changes increasing seizure probability in severe cases, as the degree of injury is exceedingly high and cannot be efficiently counteracted, or that the secondary detrimental effects continue to develop over a longer time frame than in moderate cases, or both. In fact, more severe HIE is associated with greater primary cerebral damage, earlier onset of secondary 
deterioration, and greater neuronal loss, but also (as we discussed above) with more prolonged metabolic derangement.

Many controversies also exist with respect to clinical scenarios falling outside currently approved guidelines, such as mild HIE, delayed cooling, post-natal collapse, late preterm infants, and infants with IVH or other types of brain injury. In animal models, late cooling (>6 hours) in the setting of severe hypoxic-ischemic injury, longer (120 hours vs. 72 hours) and deeper cooling $\left(32^{\circ} \mathrm{C}\right.$ vs. $\left.33.5^{\circ} \mathrm{C}\right)$ are not beneficial and may prove detrimental $[98,99]$. We already discussed above the critical role of time in the sequential changes during hypoxic-ischemic events. This results in the same interventions to possibly determine different effects when administered in different phases. The short latent phase before secondary cellular deterioration is the period during which therapeutic interventions are most likely to improve outcome. This is true for blood flow restoration, as well as for glucose levels [100]. It is also likely that maturational changes in the developing brain account for higher vulnerability of preterm infants compared to fullterm infants. Moreover, the higher incidence of adverse effects can also negatively affect outcome. Clinical studies evaluating infants not satisfying current cooling criteria document potential areas of intervention, but also a need for caution in specific sub-populations. In fact, in a retrospective observational study, no significant differences in 2-year neurodevelopmental outcomes were found in infants cooled according to or outside the standard entry criteria [101], except for newborns with severe degrees of intracranial hemorrhage, experiencing high rates of coagulopathy, death or disability. A retrospective cohort of preterm infants $<36$ weeks' gestation with HIE receiving whole body hypothermia documented death or moderate to severe neurodevelopmental impairment at 18-24 months in 50\% infants with known 
outcomes [102], and some studies documented increased incidence of hyperglycemia and leukopenia, more frequent and severe brain injury patterns, and death [103].

\subsection{Haemodynamic management}

Hemodynamic management aiming at optimizing autoregulation can be considered as an adjunctive therapeutic strategy to hypothermia in HIE. In a study on newborns, the mean arterial blood pressure "with optimized autoregulatory function" was measured in order to evaluate autoregulation. An association between greater duration and deviation of blood pressure below the optimal values and greater injury in the paracentral gyri and white matter was documented, while optimal mean values were related to lesser injury in the white matter, putamen, globus pallidus, and brainstem. Finally, higher blood pressure levels were associated with reduced injury in the paracentral gyri [104].

\subsection{Pharmacological agents}

\subsubsection{Allopurinol}

Allopurinol has anti-oxidant properties through xanthine oxidase inhibition, chelation of unbound iron and scavenging of free hydroxyl radicals. It also preserves NMDAR integrity [105]. While in preclinical studies it was shown to decrease brain injury in rodent models in the acute phase of hypoxic-ischemic brain injury [106], data in human neonates have been more conflicting.

When administered intravenously at $40 \mathrm{mg} / \mathrm{kg}$ within 4 hours of birth in severe HIE, it decreased serum-free radical levels, and improved cerebral blood flow, with no toxicity [107]. A small randomized control trial tested the same dose within 2 hours of birth and then repeated daily in the first 3 days of life for term newborns with mild, moderate, or severe encephalopathy [108]. Better developmental outcome at 12 
months was documented compared with placebo. In a follow-up study of neonates enrolled in these two trials, neurodevelopmental and cognitive outcomes at 4 to 8 years showed no difference in adverse developmental outcomes between treatment and control groups, although a significant decrease in the risk of severe adverse outcome (death or severe disability) was found in a subgroup analysis in moderate HIE [109]. The need to exclude the most severe cases in order to find impact on outcomes raises the question of not gaining any advantage if treatment commences when brain damage is too severe. Therefore, a randomized multi-center placebocontrolled trial was performed on women in labour during suspected fetal hypoxia, but failed to improve long-term developmental and behavioral outcome at 5 years of age [110].

\subsection{Xenon}

Xenon is a monoatomic gas with very high tissue solubility. It is a non-competitive inhibitor of NMDA glutamate receptor, with proven antiapoptotic and neuroprotective effects following hypoxic-ischaemic injury in animals. Out of fourteen human newborns treated with $30 \%$ inhaled xenon for $24 \mathrm{~h}$ combined with $72 \mathrm{~h}$ of moderate systemic hypothermia, five had seizures, for which they received phenytoin and/or phenobarbital and which stopped during xenon therapy, but recurred within a few minutes after withdrawal. Xenon displayed an anticonvulsant and EEG depressant effect at substantially lower doses than anaesthetic ones [111].

\subsubsection{Magnesium}

Magnesium links to NMDA channels in a voltage-dependent manner and was proposed for clinical use to contrast glutamate excito-toxicity in order to protect the developing brain from NMDAR-mediated injury $[112,113]$. Its effects in clinical cohorts of newborns with HIE were evaluated by a meta-analysis with the primary 
aim to assess the composite outcome of death or moderate-to-severe neurodevelopmental disability at 18 months. Magnesium was administered within the first 24 hours after birth with one of the following schemes: three doses of $250 \mathrm{mg} / \mathrm{kg}$ per dose 24-h apart [114,115] plus dopamine $5 \mathrm{mg} / \mathrm{kg} / \mathrm{min}$ in [116] or $250 \mathrm{mg} / \mathrm{kg}$ within 30 minutes of birth followed by $125 \mathrm{mg} / \mathrm{kg}$ at 24 and $48 \mathrm{~h}[117,118]$. The authors found no difference in the composite primary outcome of death or moderateto-severe neurodevelopmental disability at age 18 months, while the short-term composite outcome of survival with abnormalities in neurodevelopmental exam, neuroimaging or neurophysiologic investigations improved [119].

A retrospective observational study of singleton pregnancies complicated by prolonged premature rupture of membranes at $23+{ }^{\circ}-31+6$ weeks receiving magnesium for tocolysis or not, documented that magnesium can prolong the latent period, and showed neuroprotective effects for neonatal IVH, periventricular leukomalacia and developmental delay during infancy. These benefits were limited to the subgroup between 23 and $27+6$ weeks' gestation. Furthermore, prolonged in utero exposure to magnesium sulphate was associated with bone mineralization [120].

\subsubsection{Melatonin}

Melatonin has antioxidant, anti-inflammatory and anti-apoptotic properties [121]. It is a scavenger for reactive oxygen and nitrogen species [122], it decreases lipid peroxidation and serum nitrite/nitrate concentrations [123], and stimulates both antioxidant enzyme activity and their mRNA levels [122]. It also reduces proinflammatory cytokines by preventing translocation of the nuclear factor-kappa B of activated B cells, reduces phospholipase A2, lipoxygenase and cyclooxygenases activation [124] and leukocytes recruitment to inflammatory sites [125] and vascular 
endothelial growth factor levels [126]. Finally, together with anti-apoptotic activity mainly targeting the mitochondria, it also enhances cell rescue pathways [121]. In a randomized controlled pilot study, newborns with HIE were allocated either to whole-body hypothermia alone or plus melatonin (five daily $10 \mathrm{mg} / \mathrm{kg}$ enteral doses). Compared with healthy newborns, patients with HIE had higher levels of serum melatonin and nitric oxide, and plasma superoxide dismutase at birth, while the two HIE groups did not differ for clinical, EEG or other laboratory characteristics. At 5 days, greater increase in melatonin and decline in nitric oxide, but less decline in superoxide dismutase were found in patients treated with hypothermia plus melatonin, and this group had fewer seizures, less brain white matter abnormalities and improved survival without neurological or developmental abnormalities (evaluated by neurological examination and Denver Developmental Screening Test II) than controls, suggesting correlation with favorable mid-term outcome. A small trial in infants with HIE randomized to receive melatonin plus hypothermia or hypothermia alone reported improved survival at 6 months of age without neurological or developmental abnormalities [127].

One of the main limitations is the unavailability of a safe intravenous solution (most contain alcohol), and risk for limited enteral absorption, especially in multi-organ failure [105].

\subsubsection{Erythropoietin}

Erythropoietin (Epo) is a cytokine originally known for its role in erythropoiesis, but also providing important functions in the central nervous system as a neuroprotective agent and a growth factor [128]. Clinical and pre-clinical studies suggest that chronic exposure to hyperoxia results in subtle, diffuse injury to the immature brain [129131], microglial activation [130, 132] induced by oxidative stress, inflammation and 
cellular degeneration, which can lead to hypomyelination and long-term cognitive deficits $[129,130]$. Importantly, such hyperoxic conditions might be unavoidable during neonatal intensive care stay.

Experimental models of preterm brain injury seem to suggest a positive effect of high dose Epo in long-term neurocognitive function in rats. In one study, 20,000 IU/kg Epo by single intraperitoneal injection at the onset of hyperoxia in P6 rats improved hyperoxia-induced oligodendrocyte degeneration with preservation of white matter structures an improved cognitive outcome by reducing hyperoxia-induced deleterious effects on neuronal plasticity [133].

Clinical studies were encouraged by positive results from experimental research. Pharmacokinetic and safety studies show that $500-3000 \mathrm{U} / \mathrm{kg}$ Epo is safe $[134,135]$. In one study, 24 newborns with HIE received a maximum of six Epo doses in addition to hypothermia. Eight (36\%) had moderate-to-severe brain injury on neonatal MRI, but just one (4.5\%) had moderate-to-severe disability at latest followup (mean age in the whole cohort: 22 months) [136]. In a retrospective cohort of extremely low birth weight infants, Epo was associated with higher cognitive and motor scores at BSID-II or BSID-III and no long-term detrimental effects (last examined at 36 months) [137]. Preterm infants born between 26 and 31 weeks +6 days of gestational age took part into a randomized, double-blind, placebo-controlled trial in which they received either recombinant human Epo $(3000 \mathrm{IU} / \mathrm{kg})$ or placebo given intravenously $<3$ hours, at $12-18$ hours, and at $36-42$ hours after birth. White matter injury was assessed at term-equivalent age by conventional brain MRI. Fewer infants treated with recombinant human erythropoietin had abnormal scores for white matter injury, white matter signal intensity, periventricular white matter loss, and gray matter injury compared to untreated infants [138]. A positive role in developmental 
processes in the preterm brain was suggested by tractography, demonstrating a diffuse (although weak) increase in the strength of local connections and a possible trophic effect, facilitating the development of peripheral and frontal, temporal, subcortical and limbic core connections [139]. However, a randomized trial on preterm infants born between 24 weeks and $27+6$ weeks of gestation receiving Epo or placebo in the first 24 hours after birth failed to document significant differences in death or severe neurodevelopmental impairment at 2 years [140]. Finally, Epo also works as a trophic factor, stimulating neurogenesis [141, 142]. Experimental studies with neonatal stroke models showed that Epo reduces infarct volume $[143,144]$ and improves motor and cognitive function $[145,146]$, up to 1 week after the onset of neonatal stroke [147]. Although experimental models and human brain MRI data seem promising, prospective, randomized case-control clinical studies with long-term follow-up are needed, using standardized neurodevelopmental scales to assess the overall, neurological and neurocognitive outcome of patients treated with Epo.

\subsubsection{Vitamin E}

Vitamin $\mathrm{E}$ is a chain-breaking antioxidant and the main lipid peroxyl radical scavenger. A meta-analysis documented reduced risk of intracranial hemorrhage but increased risk of sepsis in preterm infants [148].

\subsubsection{Caffeine}

Caffeine reduces the incidence of bronchopulmonary dysplasia and improves survival without neurodevelopmental disability when used for apnoea of prematurity [149].

However, caution is required in its use outside this indication. First of all, prenatal exposure predisposes to intrauterine growth restriction and small growth for gestational age at birth. Even more importantly, in animal models, exposure during 
pregnancy and breast-feeding seems to adversely affect neuronal development. The potential for multiple impacts on developing brain derives, first of all, from its role as a non-selective antagonist on adenosine receptors [150], which are highly expressed in the immature brain with a modulating role [151], thus their inactivation can result in precocious oligodendrocytes maturation, possibly leading to reduced oligodendrocytes pool in later life. Additionally, aside from acting as a free radicals scavenger, caffeine also inhibits phosphodiesterases, promoting intracellular calcium release and interfering with GABA-A receptors [152]. In fact, the development of GABAergic neuronal networks in the primary visual cortex was shown to be affected by caffeine in rats, with increased synaptic activity in vitro and elevated network activity in vivo. Similarly, in vivo abnormalities in hippocampal network activity were found in the neonatal period, persisting until adulthood. Most importantly, animal data suggest increased seizure susceptibility in a hyperthermia-induced seizure model [153], and both a trend towards increased seizure incidence and a three-fold increase in seizure burden [154] in a secondary post-hoc analysis of a trial of early high-dose caffeine citrate administration to preterm infants, aiming to improve white matter microstructural development [155].

Caffeine also increases oxygen extraction, suggesting transient stimulating effect on brain metabolism. However, in a cohort of preterm babies $<32$ weeks of gestational age, no significant changes occurred in brain perfusion or in electrical brain activity when exposed to $10 \mathrm{mg} / \mathrm{kg}$ caffeine [155], even if a different study, using Doppler ultrasound, showed decreased CBF velocity [156].

Finally, phenobarbital-mediated impaired neurogenesis was largely restored by 10 $\mathrm{mg} / \mathrm{kg}$ caffeine preconditioning [157], and this finding might pave the way to new lines of research. 


\subsection{Mesenchymal stem cells and neurotrophic factors}

Neurotrophic factors and mesenchymal stem cells (MSCs) have been studied in experimental models of stroke and intracranial hemorrhage. The state of the art on their use in perinatal arterial ischemic stroke (PAIS) has been recently reviewed [158].

MSC treatment reduces infarct volume and blood-brain barrier disruption and increases angiogenesis, leading to neurovascular repair and improved cerebral blood flow. They also stimulate neurogenesis [159]. These effects are thought to be reached by a paracrine effect [158], as the majority of these cells do not survive more than 72 hours [160].

One of the main issues in applying neuroprotection to PAIS is that its neurological signs become apparent after the therapeutic time window [158]. A correlation between neurotrophic factors and progenitor cells in serum and the severity and outcome of ischemic stroke has been documented in adults [161], while abnormal levels of neurotrophic factors were detected in newborns with various perinatal brain insults, including HIE, hydrocephalus, and IVH, although not PAIS, in some cases correlating with the severity of brain injury [162-164]. Autologous umbilical cord blood cells have been safely administered to neonates with HIE [165]. Reduced levels of VEGF receptor-2 after neonatal stroke worsen injury, increase cell death, and reduce endothelial cell proliferation in rats, indicating a role for vascular endothelial growth factor (VEGF) signaling in repair after ischemic injury and in neuroprotection against apoptosis [166]. Importantly, motor and cognitive functions are also improved and brain infarct volume is attenuated [167]. Epidermal growth factor (EGF) and insulinlike growth factor (IGF-1) showed beneficial effects in experimental models of 
preterm white matter injury. Selective overexpression of human EGF receptor in oligodendrocyte $(\mathrm{OL})$ lineage cells and intranasal administration of EGF immediately after injury decreased OL death and induced generation of new OLs from progenitor cells [168]. IGF-1 also showed protective effects in newborn animals and in cultured pre-OLs [169], with positive functional effects in immature rats [170]. Intranasallyadministered stem cells in rat models of preterm injury mitigate myelin injury and improve behavioral outcome $[160,171]$. In a different experimental model of preterm white matter injury, transplantation of OL progenitor cells produced from embryonic stem cells resulted in their successful differentiation, myelin sheath formation, and proliferation of endogenous neural stem cells. Functional benefits were also documented at 6 weeks [172].

\subsection{Antiseizure medications}

Based on the contribution of acute seizures in increasing the detrimental effects of the initial brain insult, a timely and effective treatment is likely to represent a critical step in protecting the newborn brain. Consequently, the first neuroprotective strategy when managing acute symptomatic seizures is effectively stopping them. As response rate is around $50 \%$ for medications used as first-line [18], and acute symptomatic seizures are self-limiting phenomena, one major issue is to find an effective and safe drug to administer. The most widely used first-line antiseizure medications include phenobarbital and phenytoin, due to the longest "real world" use and evidence from randomized controlled trials [18]. However, due to concerns relating to their safety, other medications are widely used, usually as second or thirdline, including benzodiazepines (midazolam, lorazepam, diazepam), or lidocaine, or have been proposed even as first-line due to safety and kinetics, such as levetiracetam, which nonetheless was documented to be less efficacious than 
phenobarbital [17], resulting in better reserving it to second or third-line treatment. Alternative drugs, such as topiramate, have more limited use due to the unavailability of an intravenous formulation (Table 1).

Additionally, there is a huge body of evidence for a potential detrimental effect of antiseizure medications. Descriptions of deleterious effects on long-term outcome, especially cognition, have been numerous, especially in animal models [173]. Results from experimental studies on immature rodent models suggest that phenobarbital can induce apoptosis, involving the cortex, hypothalamus, thalamus, basal ganglia and the white matter [174-176]. However, the average phenobarbital dose in these studies was much higher than typical doses administered to human neonates $(75 \mathrm{mg} / \mathrm{kg})$ [177]. These same loading doses were associated with detrimental long-term effects, including schizophrenia-like behavior and impaired learning, memory, and social interactions [178]. Both phenobarbital and phenytoin interfere with synaptic maturation of neonatal rat brain and impair behavior [177]. Large doses of phenytoin $(50 \mathrm{mg} / \mathrm{kg}$ ) cause similar effects to phenobarbital, with apoptosis and synaptic disruption in the developing brain [176, 177]. On the contrary, levetiracetam showed mixed results. A loading dose of $80 \mathrm{mg} / \mathrm{kg}$ and a $40 \mathrm{mg} / \mathrm{kg}$ maintenance daily dose in the hypoxic-ischemic rat resulted in decreased apoptosis, suggesting a neuroprotective role [179], possibly linked to increased expression of superoxide dismutase and glutathione peroxidase [180]. Interestingly, in a different model, a dose of $50 \mathrm{~m} / \mathrm{kg}$ every $12 \mathrm{~h}$ for 3 days increased brain injury under normothermic conditions, but not under hypothermic conditions [181], highlighting the need to use models recapitulating clinical scenarios and always evaluating hypothermic conditions in models of full term perinatal brain injury, as this is the current standard of care, and might impact on results in a clinically relevant way. A 
recent study on levetiracetam use during therapeutic hypothermia in rats demonstrated dose-dependent occurrence of apoptosis, not documented at low doses [182]. A clinical study comparing levetiracetam $(20 \mathrm{mg} / \mathrm{kg}$ increased by 10 $\mathrm{mg} / \mathrm{kg}$ up to $40-60 \mathrm{mg} / \mathrm{kg}$ ) and phenobarbital $(20 \mathrm{mg} / \mathrm{kg}$ increased by $10 \mathrm{mg} / \mathrm{kg}$ up to $40 \mathrm{mg} / \mathrm{kg}$ ) monotherapy for clinical neonatal seizures, for a mean duration of $8 \pm 6$ months documented no significant differences in neurocognitive outcome [183]. In the lack of high quality evidence, four main strategies exist in order to protect the developing brain: choosing the right time for their administration and withdrawal, avoiding deleterious drugs, favoring drugs without pro-apoptotic or with neuroprotective effects, and adding neuroprotective agents to anti-seizure medications in order to counteract their potentially deleterious effect. Although no guidelines currently define the correct timing for treatment, the goal of a prompt treatment seems to be often missed [184]. As a high seizure burden and especially status epilepticus are associated with worse brain injury and worse longterm outcomes, correct timing in drug administration is likely to be crucial in lowering seizure burden [51], and providing the best balance between effectiveness and side effects. In fact, after prolonged seizures, activity-dependent NKCC (sodiumpotassium-chloride channel) changes lead to a shift back towards an excitatory effect of GABA due to chloride accumulation mediated by NKCC1 receptors with downregulation and internalization of chloride-potassium cotransporter 2 (KCC2) receptors, thus lowering drug efficacy. [185] Even more concernedly, detrimental effects were demonstrated in case of late phenobarbital administration in an experimental model: while early phenobarbital was associated with reduced ictal-like events and prevention of a mirror focus, the epileptiform activity was even 
aggravated by late phenobarbital administration (after repeated ictal-like events) [186].

If antiseizure medications have a potential for long-term detrimental effects, time is also a critical player with respect to their withdrawal. Even if no guidance and no clear-cut evidence exist, some papers documented that early discontinuation at discharge in newborns with HIE [187] or different aetiologies [188] is not associated with an increased risk of seizure recurrence [187] nor with any differences in neurological development [188]. However, although a shift towards less treatment and shorter treatment duration after seizures resolution has been documented over time, significant inconsistencies seem to persist in clinical practice [189]. The presence of brain injury at MRI was associated with a trend towards higher risk of seizures during follow-up period. Therefore, in the context of HIE, patients experiencing few seizures with response to medications, mildly abnormal EEG and absence of severe brain MRI injury are considered as candidates for early drug withdrawal [187].

Among antiseizure medications with evidence of a neuroprotective effect, topiramate is probably the most widely studied in newborns. It acts by inhibiting AMPA and kainate receptors and potentiating GABA signaling, resulting in dose-dependent brain injury reduction, and neurobehavioural improvement in animal models [190]. Preclinical studies suggest a synergistic effect with hypothermia [191-193]. Safety pilot studies documented no statistically or clinically significant differences for safety, death or severe neurologic disability, but a lower prevalence of epilepsy in newborns treated with topiramate (10 mg/kg/day) and hypothermia compared to controls [194]. In a randomized, controlled, multicentre, double-blind study, the use of topiramate (5 $\mathrm{mg} / \mathrm{kg}$ loading dose, followed by $3 \mathrm{mg} / \mathrm{kg}$ maintenance dose) in newborns with HIE 
correlated with lower seizure burden in the first 24 hours of hypothermia, less need for additional antiseizure medications and lower mortality, although not statistically significant. However, of the utmost importance, only $37.5 \%$ of the patients achieved therapeutic levels within the first 24 hours, and $75.5 \%$ at 48 hours [195]. There is a critical issue regarding pharmacokinetics under hypothermic conditions, which might undermine topiramate efficacy during the latent period, as an intravenous formulation is unavailable, and underdosing might have impacted on study results.

Clinical trials administering drugs with a mechanism of action directed to the immature brain have failed to provide additional benefit, as it is the case for bumetanide, a loop diuretic acting as a NKCC1 (Na-K-Cl) transporter, which was proven to increase phenobarbital efficacy in animal models [196-197], but caused hearing loss and failed to demonstrate efficacy (defined as $80 \%$ seizure reduction) in an open-label feasibility study on human newborns, determining its early termination [198].

However, an interesting experimental study investigated a lipophilic bumetanide derivative (bumepamine), which exhibits higher brain penetration than bumetanide, and found it more potent than bumetanide in potentiating phenobarbital anticonvulsant effect in two rodent models of epilepsy, despite lower inhibition of the NKCC1 channel, thus suggesting the existence of alternative mechanisms of action [199], which should be further investigated and also applied to acute symptomatic seizure models, before definite conclusions can be drawn in the context of perinatal brain injury and symptomatic neonatal seizures.

A promising additional strategy to stop or prevent acute symptomatic neonatal seizures is represented by $\mathrm{Kv} 7(\mathrm{KCNQ})$ channel openers, such as flupirtine. This drug has been proven to act more efficaciously than diazepam and phenobarbital in 
rat models of kainic acid and fluorothyl induced neonatal seizures, by completely preventing or stopping seizures after the injection of the chemoconvulsants [200]. In a further rat model of global hypoxia, flupirtine was shown to dose-dependently stop behavioural seizures during hypoxia and to inhibit electroclinical seizures and electrographic seizures. However, in this study, flupirtine was administered before the insult took place, and therefore further studies should explore the time window for its use, with special emphasis to the reperfusion phase of hypoxic-ischemic events [201]. However, a rationale for a favourable effect of flupirtine and its analogues on acute symptomatic seizures and neuroprotection in the context of therapeutic hypothermia is also suggested by their dose-dependent hypomotor, sedative and hypothermic effect in mice [202].

\section{Neurorestorative interventions}

In a recent and exhaustive review on white matter injury in preterm infants, it was acknowledged that, aside from the acute detrimental effects resulting in pre-OL death, secondary long-term changes take place, resulting in dysmaturation. This late, developmentally-regulated phase involves activated microglia and reactive astrocytes, and offers a longer time window for therapeutic interventions, including pharmacological approaches, stem cell therapy (outlined above), but also nutritional (breastfeeding, polyunsaturated fatty acids, iron, zinc) and experiential factors (optimal auditory and visual exposure, minimization of pain and stress, environmental enrichment) [84]. "Extra-uterine" preterm newborns have reduced cerebral and cerebellar volumes, cortical gyrification, delayed maturation [40] and impaired functional connectivity compared to their counterparts [203]. Aside from a negative role of specific therapies, including dexamethasone, and the negative role of hyperoxia, hypocapnia, blood pressure changes, 
hypo/hyperglycemia [22], the effects of the neonatal intensive care unit (NICU) environment itself have been studied, with respect to noise, lights and early life stimulation, with conflicting results [204, 205]. Pain and stress in the neonatal period have also been suggested to result in negative neurobehavioural and cognitive outcomes and to correlate with cerebral functional connectivity [206]. Nutritional factors have a crucial role in immature brain development. During the last trimester of pregnancy, transplacental transfer of polyunsaturated fatty acids (PUFA) contributes to neural membranes formation, and their reduced levels in preterm-born infants have been shown to correlate with micro and macrostructural white and grey matter characteristics at term-equivalent age [207, 208].

\section{Expert opinion}

For the time being, only therapeutic hypothermia has been demonstrated to result both in clinically significant outcome improvement and in reduction of seizure burden and later epilepsy. Apart from associating hypothermia with prophylactic antiseizure medications, the effects of neuroprotective interventions in reducing acute seizure burden and the possible long-term beneficial effects have not been directly investigated. This field would give unique insights into the independent role of seizures in worsening outcome.

As seizures likely contribute to brain injury exacerbation by further activating the same pathways as the initial deleterious event causing them, strategies addressing key involved players (oxidative stress, inflammation, hemodynamic changes) might result in a positive effect on both brain injury and seizures, and consequently on clinically meaningful outcomes. However, the occurrence of seizures, in many conditions, announces the end of the latent period and the activation of multiple cascades of detrimental events, which should be best prevented rather than treated, 
although so far such (including prenatal) strategies have not been successful, except hypothermia. The issue is, this lack of significant results might have multiple explanations, and therefore future studies should aim to control the number of confounding variables. Additional factors, from gestational age, to choice of correct timing and dosing for each drug, possibly lead to inconsistencies in study results. Further complicating this subject, the window of opportunity for neuroprotective actions is limited and might change depending on gestational age, severity of brain injury, etiology, and other -possibly still unknown- factors.

A huge body of data has been collected in animal models and further effort should be made in constructing specific models addressing the unique characteristics of different gestational ages, etiologies, degrees of brain injury, timing of insult and of administration and dosing of neuroprotective agents. When studying post-mortem specimen (possibly after behavioural testing), it would be important to analyze specific, more susceptible brain areas according to gestational ages and their functionally-linked networks, depending on the specifically analyzed outcome (i.e. epilepsy, cognition, motor function). In fact, for some brain structures, such as the cerebellum, the white matter or the frontal lobes, maturational processes continue postnatally and might be the target of specific neurorestorative interventions. Furthermore, better understanding and comparability of studied outcomes is warranted. Systemic, neurological and cognitive outcomes need to be prospectively collected with standardized scales. It is also important to identify reliable and clinically relevant biomarkers since the earliest stages of the pre/perinatal period. To this end, research on new neuroimaging tools might become increasingly useful (tractography, spectroscopy, perfusion analysis, NIRS, functional connectivity, microstructural changes), and increasingly available in the future, and may possibly 
provide deeper insight into the relationships between seizures, brain injury and outcome.

In the meantime, providing evidence-based supportive care during the NICU stay is useful in improving outcome by controlling systemic factors involved in worsening of brain injury, especially in complex patients.

In five years' time, results from trials on therapeutic hypothermia in preterm infants will be available, as well as more clinical trials on allopurinol, erythropoietin, xenon and melatonin in hypoxic-ischemic encephalopathy and neuroprotective strategies for preterm infants, including administration of melatonin, erythropoietin, magnesium with respect to white matter injury. Trials are also recruiting patients in order to collect brain MRI data following neuroprotective interventions and to address the effects of NICU environment on newborns. A placebo-controlled study on enteral topiramate for neonates under hypothermia for HIE is also expected to be completed in 2022 and will report on the rate of neonatal seizures in the two groups. Additional options for acute seizure management might also become available once studies currently under way for brivaracetam and lacosamide are completed (www.clinicaltrials.gov, last visited on 21st October 2020). Hopefully, based on results of these ongoing studies, better care will be provided.

\section{Figure and table legends}

Figure 1. Neuroprotective interventions for fullterm newborns with HIE according to the phase and timing of their action. (HIE: hypoxic-ischemic encephalopathy)

Figure 2. Neuroprotective and neurorestorative interventions for preterm newborns.

Table 1. Antiseizure medications for acute symptomatic neonatal seizures: dosing, order and route of administration, with reference to the pertinent literature. 


\section{Funding}

This paper was not funded.

\section{Declaration of interests}

The authors have no relevant affiliations or financial involvement with any organization or entity with a financial interest in or financial conflict with the subject matter or materials discussed in the manuscript. This includes employment, consultancies, honoraria, stock ownership or options, expert testimony, grants or patents received or pending, or royalties.

\section{Reviewer disclosures}

Peer reviewers on this manuscript have no relevant financial or other relationships to disclose.

\section{References}

Papers of special note have been highlighted as either of interest $\left(^{*}\right)$ or of considerable interest $\left.{ }^{* *}\right)$ to readers.

1. Pisani F, Facini C, Bianchi E, et al. Incidence of neonatal seizures, perinatal risk

factors for epilepsy and mortality after neonatal seizures in the province of Parma, Italy. Epilepsia. 2018;59:1764-73

2. Pisani F, Fusco C, Spagnoli C. Linking acute symptomatic neonatal seizures, brain injury and outcome in preterm infants. Epilepsy Behav. 2020;112:107406

3. Vasudevan C, Levene M. Epidemiology and aetiology of neonatal seizures. Semin

Fetal Neonatal Med. 2013;18:185-91

4. Clancy RR, Legido A. The exact ictal and interictal duration of

electroencephalographic neonatal seizures. Epilepsia. 1987;28:537-41

5. Volpe JJ. Neonatal seizures: current concepts and revised classification.

Pediatrics. 1989;84:422-8

6. Lombroso CT. Neonatal seizures: historic note and present controversies.

Epilepsia. 1996;37:5-13

7. Mizrahi EM, Kellaway P. Characterization and classification of neonatal seizures.

Neurology. 1987;37:1837-44 
8. Nagarajan L, Palumbo L, Ghosh S. Classification of clinical semiology in epileptic seizures in neonates. Eur J Paediatr Neurol. 2012;16:118-25

9. Pisani F, Pavlidis E. The role of electroencephalogram in neonatal seizure detection. Expert Rev Neurother. 2018;18:95-100

10. Rakshasbhuvankar A, Rao S, Palumbo L, et al. Amplitude Integrated Electroencephalography Compared With Conventional Video EEG for Neonatal Seizure Detection: A Diagnostic Accuracy Study. J Child Neurol. 2017;32:815-22 11. Nagarajan L, Ghosh S, Palumbo L. Ictal electroencephalograms in neonatal seizures: characteristics and associations. Pediatr Neurol. 2011;45:11-6 12. Murray DM, Boylan GB, Ali I, et al. Defining the gap between electrographic seizure burden, clinical expression and staff recognition of neonatal seizures. Arch Dis Child Fetal Neonatal Ed. 2008;93:F187-91

13. Malone A, Ryan CA, Fitzgerald A, et al. Interobserver agreement in neonatal seizure identification. Epilepsia. 2009;50:2097-101

14. McBride MC, Laroia N, Guillet R. Electrographic seizures in neonates correlate with poor neurodevelopmental outcome. Neurology. 2000;55:506-13 15. Shellhaas RA, Chang T, Tsuchida T, et al. The American Clinical Neurophysiology Society's Guideline on Continuous Electroencephalography Monitoring in Neonates. J Clin Neurophysiol. 2011;28:611-17

16. Slaughter LA, Patel AD, Slaughter JL. Pharmacological treatment of neonatal seizures: a systematic review. J Child Neurol. 2013;28:351-64

17. Sharpe C, Reiner GE, Davis SL, et al. NEOLEV2 INVESTIGATORS. Levetiracetam 
Versus Phenobarbital for Neonatal Seizures: A Randomized Controlled Trial.

Pediatrics. 2020;145:e20193182

18. Painter MJ, Scher MS, Stein AD, et al. Phenobarbital compared with phenytoin for the treatment of neonatal seizures. N Engl J Med. 1999;341:485-9

19. Spagnoli C, Seri S, Pavlidis E, et al. Phenobarbital for Neonatal Seizures:

Response Rate and Predictors of Refractoriness. Neuropediatrics. 2016;47:318-26

20. Glass HC, Shellhaas RA, Tsuchida TH, et al. Seizures in Preterm Neonates: A Multicenter

Observational Cohort Study. Pediatr Neurol. 2017;72,19-24

21. Boylan GB, Rennie JM, Pressler RM, et al. Phenobarbitone, neonatal seizures, and video- EEG. Arch Dis Child Fetal Neonatal Ed. 2002;86:F165-70

22. Glass HC, Costarino AT, Stayer SA, et al. Outcomes for extremely premature infants. Anesth Analg. 2015;120:1337-51

23. Andreolli A, Turco EC, Pedrazzi G, et al. Incidence of Epilepsy after Neonatal Seizures: A

Population-Based Study. Neuroepidemiology. 2019;52:144-51

24. Pisani F, Facini C, Pavlidis E, et al. Epilepsy after neonatal seizures: literature review. Eur. J. Paediatr. Neurol. 2015;19:6-14

25. Pisani F, Barilli AM, Sisti L, et al. Preterm infants with video-EEG confirmed seizures: outcome at 30 months of age. Brain Dev. 2008;30:20-30

26. Pisani F, Copioli C, Di Gioia C, et al. Neonatal seizures: relation of ictal videoelectroencephalography findings with neurodevelopmental outcome. J Child Neurol. 2008;23:394-8

27. Pisani F, Facini C, Pelosi A, et al. Neonatal seizures in preterm newborns: A predictive model for outcome. Eur J Paediatr Neurol. 2016; 20:243-51 
28. Dwivedi D, Lin N, Venkatesan C, et al. Clinical, Neuroimaging, and Electrographic

Predictors of Phenobarbital Failure in Newborns With Hypoxic Ischemic Encephalopathy and Seizures. J Child Neurol. 2019;34:458-63

29. Pisani F, Sisti L, Seri S. A scoring system for early prognostic assessment after neonatal seizures. Pediatrics. 2009;124:580-7

30. Garfinkle J, Shevell MI. Prognostic factors and development of a scoring system for outcome of neonatal seizures in term infants. Eur J Paediatr Neurol. 2011;15:2229

31. Johnston MV, Fatemi A, Wilson MA, Northington F. Treatment advances in neonatal neuroprotection and neurointensive care. Lancet Neurol. 2011;10:372-82 32. Sarnat HB, Sarnat MS. Neonatal encephalopathy following fetal distress. A clinical and electroencephalographic study. Arch Neurol. 1976;33:696-705 33. Hope PL, Costello AM, Cady EB, et al. Cerebral energy metabolism studied with phosphorus NMR spectroscopy in normal and birth-asphyxiated infants. Lancet. 1984;2: $366-70$

34. Hope PL, Reynolds EO. Investigation of cerebral energy metabolism in newborn infants by phosphorus nuclear magnetic resonance spectroscopy. Clin Perinatol. $1985 ; 12: 261-75$

35. Ferriero DM. Neonatal brain injury. N Engl J Med. 2004;351:1985-95

36. Johnston MV. Excitotoxicity in perinatal brain injury. Brain Pathol. 2005;15:23440

37. Johnston MV, Trescher WH, Ishida A, et al. Neurobiology of hypoxic-ischemic injury in the developing brain. Pediatric Res. 2001;49:735-41 
38. Ben-Ari Y, Holmes GL. Effects of seizures on developmental processes in the immature brain. Lancet Neurol. 2006;5:1055-63**A comprehensive and exhaustive review of the experimental data supporting a detrimental effect of neonatal seizures in long-term neurological outcomes and their underlying mechanisms.

39. Jensen FE. The role of glutamate receptor maturation in perinatal seizures and brain injury. Int J Dev Neurosci. 2002; 20:339-47

40. Volpe JJ. Brain injury in premature infants: a complex amalgam of destructive and developmental disturbances. Lancet Neurol. 2009;8:110-124.

41. Kidokoro H, Anderson PJ, Doyle LW, et al. Brain injury and altered brain growth in preterm infants: predictors and prognosis. Pediatrics. 2014;134:e444-53

42. Vesoulis ZA and Mathur AM. Cerebral Autoregulation, Brain Injury, and the Transitioning Premature Infant. Front Pediatr. 2017;5:64

43. Lein ES, Finney EM, McQuillen PS, et al. Subplate neuron ablation alters neurotrophin expression and ocular dominance column formation. Proc Natl Acad Sci USA 1999;96:13491-5

44. McQuillen PS, Sheldon RA, Shatz CJ, et al. Selective vulnerability of subplate neurons after early neonatal hypoxiaischemia. J. Neurosci. 2003;23:3308-3315 45. Fleiss B, Tann CJ, Degos V, et al. Inflammation-induced sensitization of the brain in term infants. Dev Med Child Neurol. 2015;57:17-28

46. Pisani F, Cerminara C, Fusco C, et al. Neonatal status epilepticus vs recurrent neonatal seizures: clinical findings and outcome. Neurology. 2007;69:2177-85

47. Nunes ML, Yozawitz EG, Zuberi S, et al. Neonatal seizures: Is there a relationship between ictal electroclinical features and etiology? A critical appraisal based on a systematic literature review. Epilepsia Open. 2019;4:10-29 
48. Glass HC, Shellhaas RA, Wusthoff CJ, et al. Contemporary Profile of Seizures in Neonates: A Prospective Cohort Study. J Pediatr. 2016; 174:98-103

49. Pavlidis E, Spagnoli C, Pelosi A, et al. Neonatal status epilepticus: differences between preterm and term newborns. Eur J Paediatr Neurol. 2015;19:314-9 50. Herman ST. Epilepsy after brain insult: targeting epileptogenesis. Neurology. 2002; 59:S21-26

51. Harris ML, Malloy KM, Lawson SN, et al. Standardized Treatment of Neonatal Status

Epilepticus Improves Outcome. J Child Neurol. 2016;31:1546-54

52. De Haan TR, Langeslag J, van der Lee JH, et al. A systematic review comparing neurodevelopmental outcome in term infants with hypoxic and vascular brain injury with and without seizures. BMC Pediatr. 2018;18:147.

53. Kharoshankaya L, Stevenson NJ, Livingstone V, et al. Seizure burden and neurodevelopmental outcome in neonates with hypoxic-ischemic encephalopathy.

Dev Med

Child Neurol. 2016;58:1242-1248

54. Fox CK, Mackay MT, Dowling MM, et al. Prolonged or recurrent acute seizures after pediatric arterial ischemic stroke are associated with increasing epilepsy risk. Dev Med

Child Neurol. 2017;59:38-44

55. van Rooij LG, Toet MC, van Huffelen AC, et al. Effect of treatment of subclinical neonatal seizures detected with aEEG: randomized, controlled trial. Pediatrics. 2010;125:e358-66 
56. Glass HC, Glidden D, Jeremy RJ, et al. Clinical neonatal seizures are independently associated with outcome in infants at risk for hypoxic-ischemic brain injury. J Pediatr 2009; 155, 318-323

57. Ramantani G, Schmitt B, Plecko B, et al. Neonatal Seizures-Are We there Yet? Neuropediatrics. 2019;50:280-293

58. Pisani F, Pavlidis E. What is new: Talk about status epilepticus in the neonatal period. Eur J Ped Neurol. 2018;22:757-762

59. Zimmermann A, Domoki F, Bari F. Seizure-induced alterations in cerebrovascular function in the neonate. Dev Neurosci. 2008;30:293-305

60. Perlman JM, Volpe JJ. Seizures in the preterm infant: effects on cerebral blood flow velocity, intracranial pressure, and arterial blood pressure. J Pediatr. $1983 ; 102: 288-93$

61. Boylan GB, Panerai RB, Rennie JM, et al. Cerebral blood flow velocity during neonatal seizures. Arch Dis Child Fetal Neonatal Ed. 1999;80:F105-F110

62. Shuhaiber H, Bolton S, Alfonso I, et al. Cerebral regional oxygen fluctuations and decline during clinically silent focal electroencephalographic seizures in a neonate. $\mathrm{J}$ Child Neurol. 2004;19:539-540

63. Boylan GB, Young K, Panerai RB, et al. Dynamic cerebral autoregulation in sick newborn infants. Pediatr Res. 2000;48:12-7

64. Pourcyrous M, Basuroy S, Tcheranova D, et al. Brain-derived circulating endothelial cells in peripheral blood of newborn infants with seizures: a potential biomarker for cerebrovascular injury. Physiol Rep. 2015;3:e12345 
65. Murray DM, Boylan GB, Fitzgerald AP, et al. Persistent lactic acidosis in neonatal hypoxic-ischaemic encephalopathy correlates with EEG grade and electrographic seizure burden. Arch Dis Child Fetal Neonatal Ed. 2008;93:F183-6

66. Fernandez F, Verdu A, Quero J, et al. Cerebrospinal fluid lactate levels in term infants with perinatal hypoxia. Pediatr Neurol. 1986;2:39-42

67. Hanrahan JD, Cox IJ, Azzopardi D, et al. Relation between proton magnetic resonance spectroscopy within 18 hours of birth asphyxia and neurodevelopment at 1 year of age. Dev Med Child Neurol. 1999;41:76-82

68. Hanrahan JD, Cox IJ, Edwards AD, et al. Persistent increases in cerebral lactate concentration after birth asphyxia. Pediatr Res. 1998;44:304-11

69. Miller SP, Weiss J, Barnwell A, et al. Seizure- associated brain injury in term newborns with perinatal asphyxia. Neurology. 2002;58:542-8

70. Wirrell EC. Neonatal seizures: to treat or not to treat? Semin Pediatr Neurol.2005;12:97- 105

71. Ikeda T, Murata Y, Quilligan EJ, et al. Foetal heart rate patterns in postasphyxiated foetal lambs with brain damage. Am J Obstet Gynecol. 1998;179:13307

72. Yager JY, Armstrong EA, Mujashita H, et al. Prolonged neonatal seizures exacerbate hypoxic-ischaemic brain damage: correlation with cerebral energy metabolism and excitatory amino acid release. Dev Neurosci. 2002;24:367-81 73. Zhang G, Raol YH, Hsu FC, et al. Effects of status epilepticus on hippocampal GABAA receptors are agedependent. Neuroscience. 2004;125:299-303 74. Zhang G, Raol YS, Hsu FC, et al. Long-term alterations in glutamate receptor and transporter expression following early-life seizures are associated with increased seizure susceptibility. J Neurochem. 2004; 88:91-101 
75. McCabe BK, Silveira DC, Cilio MR, et al. Reduced neurogenesis after neonatal seizures. J Neurosci. 2001;21:2094-103

76. Liu Z, Yang Y, Silveira DC, et al. Consequences of recurrent seizures during early brain development. Neuroscience. 1999; 92:1443-54

77. Holmes GL, Gairsa JL, Chevassus-Au-Louis N, et al. Consequences of neonatal seizures in the rat: morphological and behavioral eff ects. Ann Neurol. 1998; 44: $845-57$

78. Holmes GL, Sarkisian M, Ben-Ari Y, et al. Mossy fiber sprouting after recurrent seizures during early development in rats. J Comp Neurol. 1999; 404: 537-53 79. Bickler PE, Gallego SM, Hansen BM. Developmental changes in intracellular calcium regulation in rat cerebral cortex during hypoxia. J Cereb Blood Flow Metab. $1993 ; 13: 811-$

19

80. Marks JD, Friedman JE, Haddad GG. Vulnerability of CA1 neurons to glutamate is developmentally regulated. Brain Res Dev Brain Res. 1996;97:194-206

81. Patel M, Li QY. Age dependence of seizure-induced oxidative stress. Neuroscience. 2003; 118: 431-37.

82. Stafstrom CE. Mother's Milk Protects the Immature Brain from Seizure-induced Cell Death. Epilepsy Curr. 2003;3:144-145

83. Parfenova H, Leffler CW, Basuroy S, et al. Antioxidant roles of heme oxygenase, carbon monoxide, and bilirubin in cerebral circulation during seizures. J Cereb Blood Flow Metab. 2012;32:1024-34

84. Volpe JJ. Dysmaturation of Premature Brain: Importance, Cellular Mechanisms, and 
Potential Interventions. Pediatr Neurol. 2019;95:42-66**An authoritative and updated review on the pathophysiology of brain injury in preterm infants and neuroprotective and neurorestorative strategies to counteract its deleterious effects.

85. Ghosh S. Development of the neonatal cerebral cortex. In: Neonatal seizures. Current management and future challenges. Edited By: L. Nagarajan. Mc Keith Press 2016

86. Wyckoff MH, Aziz K, Escobedo MB, et al. Part 13: neonatal resuscitation: 2015 American

Heart Association guidelines update for cardiopulmonary resuscitation and emergency cardiovascular care. Circulation.2015;132:S543-S560

87. Azzopardi D, Strohm B, Marlow N, et al; TOBY Study Group. Effects of hypothermia for perinatal asphyxia on childhood outcomes. N Engl J Med. $2014 ; 371: 140-9$

88. Guillet R, Edwards AD, Thoresen M, et al. Seven- to eight-year follow-up of the CoolCap trial of head cooling for neonatal encephalopathy. Pediatr Res. $2012 ; 71: 205-9$

89. Edwards AD, Brocklehurst P, Gunn AJ, et al. Neurological outcomes at 18 months of age after moderate hypothermia for perinatal hypoxic ischaemic encephalopathy: synthesis and meta-analysis of trial data. BMJ. 2010;340:c363 90. Liu X, Jary S, Cowan F, et al. Reduced infancy and childhood epilepsy following hypothermia-treated neonatal encephalopathy. Epilepsia. 2017;58:1902-1

91. Gunn AJ, Thoresen M. Hypothermic neuroprotection. NeuroRx. 2006;3:154-69

92. Jacobs SE, Berg M, Hunt R, et al. Cooling for newborns with hypoxic-ischemic encephalopathy. Cochrane Database Syst Rev. 2013;1:CD003311 
93. Shah PS. Hypothermia: a systematic review and meta-analysis of clinical trials. Semin Fetal Neonatal Med. 2010;15:238-46

94. Low E, Boylan GB, Mathieson SR, et al.. Cooling and seizure burden in term neonates: an observational study. Arch Dis Child Fetal Neonatal Ed. 2012; 97:F267F272

95. Srinivasakumar P, Zempel J, Wallendorf $\mathrm{M}$, et al. Therapeutic hypothermia in neonatal hypoxic ischemic encephalopathy: electrographic seizures and magnetic resonance imaging evidence of injury. J Pediatr. 2013; 163:465-470

96. Harbert MJ, Tam EW, Glass HC, et al. Hypothermia is correlated with seizure absence in perinatal stroke. J Child Neurol. 2011; 26:1126-130.

97. Orbach SA, Bonifacio SL, Kuzniewicz MW, et al. Lower incidence of seizure among neonates treated with therapeutic hypothermia. J Child Neurol. 2014;29:1502-1507

98. Thoresen M, Satas S, Løberg EM, et al. Twenty-four hours of mild hypothermia in unsedated newborn pigs starting after a severe global hypoxicischemic insult is not neuroprotective. Pediatr Res. 2001; 50: 405-11

99. Roelfsema V, Bennet L, George S, et al. Window of opportunity of cerebral hypothermia for post-ischemic white matter injury in the near-term fetal sheep. $\mathrm{J}$ Cereb Blood Flow Metab. 2004;24:877-86

100. Hammerman C, Kaplan M. Ischemia and reperfusion injury. The ultimate pathophysiologic paradox. Clin Perinatol. 1998;25:757-77

101. Smit E, Liu X, Jary S, et al. Cooling neonates who do not fulfil the standard cooling criteria - short- and longterm outcomes. Acta Paediatr. 2015;104:138-45 
102. Herrera TI, Edwards L, Malcolm WF, et al. Outcomes of preterm infants treated with hypothermia for hypoxic-ischemic encephalopathy. Early Hum Dev. 2018;125:17

103. Rao R, Trivedi S, Vesoulis Z, et al. Safety and short-term outcomes of therapeutic hypothermia in preterm neonates 34-35 weeks gestational age with hypoxic-ischemic encephalopathy. J Pediatr. 2017;183:37-42

104. Lee JK, Poretti A, Perin J, et al. Optimizing Cerebral Autoregulation May Decrease Neonatal Regional Hypoxic-Ischemic Brain Injury. Dev Neurosci. $2017 ; 39: 248-256$

105. Solevåg AL, Schmölzer GM, Cheung PY. Novel interventions to reduce oxidative- stress related brain injury in neonatal asphyxia. Free Radic Biol Med. $2019 ; 142: 113-122$

106. Palmer C, Towfighi J, Roberts RL, et al. Allopurinol administered after inducing hypoxia-ischemia reduces brain injury in 7-day-old rats. Pediatr Res. 1993;33: 40511

107. Van Bel F, Shadid M, Moison RM, et al. Effect of allopurinol on postasphyxial free radical formation, cerebral hemodynamics, and electrical brain activity. Pediatrics. 1998;101:185-93

108. Gunes T, Ozturk MA, Koklu E, et al. Effect of allopurinol supplementation on nitric oxide levels in asphyxiated newborns. Pediatr Neurol. 2007;36:17-24 109. Kaandorp JJ, Van Bel F, Veen S, et al. Long-term neuroprotective effects of allopurinol after moderate perinatal asphyxia: follow-up of two randomised controlled trials. Arch Dis Child Fetal Neonatal Ed. 2012;97: F162-F166*Follow-up results of randomised controlled trials on the use of allopurinol in moderate HIE. 
110. Klumper J, Kaandorp JJ, Schuit E, et al. Behavioral and neurodevelopmental outcome of children after maternal allopurinol administration during suspected fetal hypoxia: 5-year follow up of the ALLO-trial. PLoS One. 2018;13: e0201063 111. Azzopardi D, Robertson NJ, Kapetanakis A, et al. Anticonvulsant effect of xenon on neonatal asphyxial seizures. Arch Dis Child Fetal Neonatal Ed. 2013;98:F437-9 112. Goldenberg RL, Rouse DJ. Preterm birth, cerebral palsy and magnesium. Nat Med. 1997; 3:146-7

113. Nowak L, Bregestovski P, Ascher P. Magnesium gates glutamate-activated channels in mouse central neurones. Nature. 1984; 307:462-5

114. Bhat MA, Charoo BA, Bhat JI, at al. Magnesium sulfate in severe perinatal asphyxia: a randomized, placebo-controlled trial. Pediatrics. 2009;123:e764-9

115. Khashaba MT, Shouman BO, Shaltout AA, et al. Excitatory amino acids and magnesium sulfate in neonatal asphyxia. Brain Dev. 2006;28:375-9

116. Ichiba H, Yokoi T, Tamai H, et al. Neurodevelopmental outcome of infants with birth asphyxia treated with magnesium sulfate. Pediatr Int. 2006;48:70-75 117. Gathwala G, Khera A, Singh J, Balhara B. Magnesium for neuroprotection in birth asphyxia. J Pediatr Neurosci. 2010;5:102-4

118. Groenendaal F, Rademaker CM, Toet MC, de Vries LS. Effects of magnesium sulphate on amplitude-integrated continuous EEG in asphyxiated term neonates. Acta Paediatr. 2002;91:1073-7

119. Tagin M, Shah PS, Lee KS. Magnesium for newborns with hypoxic-ischemic encephalopathy: a systematic review and meta-analysis. J Perinatol. 2013;33:663-9 
120. Jung EJ, Byun JM, Kim YN, et al. Antenatal magnesium sulfate for both tocolysis and fetal neuroprotection in premature rupture of the membranes before 32 weeks' gestation. J Matern Fetal Neonatal Med. 2018;31:1431-1441

121. Alonso-Alconada D, Alvarez A, Arteaga O, et al. Neuroprotective effect of melatonin: a novel therapy against perinatal hypoxia-ischemia. Int J Mol Sci. 2013; 14:9379-95

122. Reiter RJ, Tan DX, Osuna C, et al. Actions of melatonin in the reduction of oxidative stress: a review. J Biomed Sci. 2000;7:444-58

123. Fulia F, Gitto E, Cuzzocrea S, et al. Increased levels of malondialdehyde and nitrite/nitrate in the blood of asphyxiated newborns: reduction by melatonin. J Pineal Res. 2001; 31: 343-9

124. Radogna F, Diederich M, Ghibelli L. Melatonin: a pleiotropic molecule regulating inflammation. Biochem Pharmacol. 2010; 80:1844-52

125. Mayo JC, Sainz RM, Tan DX, et al. Antiinflammatory actions of melatonin and its metabolites, N1-acetyl-N2-formyl-5- methoxykynuramine (AFMK) and N1-acetyl5- methoxykynuramine (AMK), in macrophages. J Neuroimmunol. 2005; 165:139-49 126. Kaur C, Sivakumar V, Lu J, et al. Melatonin attenuates hypoxiainduced ultrastructural changes and increased vascular permeability in the developing hippocampus. Brain Pathol. 2008; 18:533-47

127. Aly $\mathrm{H}$, Elmahdy $\mathrm{H}$, El-Dib $\mathrm{M}$, et al. Melatonin use for neuroprotection in perinatal asphyxia: a randomized controlled pilot study. J Perinatol. 2015;35:186-91

128. Jantzie LL, Miller RH, Robinson S. Erythropoietin signaling promotes oligodendrocyte development following prenatal systemic hypoxic-ischemic brain injury. Pediatr Res. 2013;74:658-67 
129. Felderhoff-Mueser U, Bittigau P, Sifringer M, et al.Oxygen causes cell death in the developing brain. Neurobiol Dis. 2004;17:273-82

130. Brehmer F, Bendix I, Prager S, et al. Interaction of Inflammation and Hyperoxia in a Rat Model of Neonatal White Matter Damage. PLoS One. 2012;7:1-13

131. Gerstner B, DeSilva TM, Genz K, et al. Hyperoxia causes maturationdependent cell death in the developing white matter. J Neurosci. 2008;28:1236-45 132. Serdar M, Herz J, Kempe K, et al. Fingolimod protects against neonatal white matter damage and long-term cognitive deficits caused by hyperoxia. Brain Behav Immun. 2016;52:106-19

133. Hoeber D, Sifringer M, van de Looij Y, et al. Erythropoietin Restores Long-Term Neurocognitive Function Involving Mechanisms of Neuronal Plasticity in a Model of Hyperoxia-Induced Preterm Brain Injury. Oxid Med Cell Longev. 2016; 2016:9247493

134. Juul SE, McPherson RJ, Bauer LA, et al. A phase I/II trial of high-dose erythropoietin in extremely low birth weight infants: pharmacokinetics and safety. Pediatrics. 2008;122:383-91

135. Fauchère JC, Dame $\mathrm{C}$, Vonthein $\mathrm{R}$ et al. An approach to using recombinant erythropoietin for neuroprotection in very preterm infants. Pediatrics. 2008; 122:37582

136. Rogers EE, Bonifacio SL, Glass HC, et al. Erythropoietin and hypothermia for hypoxic-ischemic encephalopathy. Pediatr Neurol. 2014;51:657-62

137. McAdams RM, McPherson RJ, Mayock DE, et al. Outcomes of extremely low birth weight infants given early high-dose erythropoietin. J Perinatol. 2013;33:226-30 138. Leuchter RH, Gui L, Poncet A, et al. Association between early administration of high-dose erythropoietin in preterm infants and brain MRI abnormality at term- 
equivalent age. JAMA. 2014;312:817-24*The study reports on the results of a randomized double-blind placebo controlled trial on 495 infants.

139. Jakab A, Ruegger C, Bucher HU, et al.; Swiss EPO Neuroprotection Trial Group. Network based statistics reveals trophic and neuroprotective effect of early high dose erythropoetin on brain connectivity in very preterm infants. Neuroimage Clin. 2019;22:101806

140. Juul SE, Comstock BA, Wadhawan R, et al.; PENUT Trial Consortium. A Randomized Trial of Erythropoietin for Neuroprotection in Preterm Infants. N Engl J Med. 2020;382:233-43.

141. Shingo T, Sorokan ST, Shimazaki T, Weiss S. Erythropoietin regulates the in vitro and in vivo production of neuronal progenitors by mammalian forebrain neural stem cells. J Neurosci. 2001; 21:9733-43

142. Osredkar D, Sall JW, Bickler PE, Ferriero DM. Erythropoietin promotes hippocampal neurogenesis in in vitro models of neonatal stroke. Neurobiol Dis. 2010;38:259-65

143. Gonzalez FF, McQuillen P, Mu D, et al. Erythropoietin enhances long-term neuroprotection and neurogenesis in neonatal stroke. Dev Neurosci. 2007;29:32130

144. Sola A, Wen T-C, Hamrick SEG, Ferriero DM. Potential for protection and repair following injury to the developing brain: a role for erythropoietin? Pediatr Res. 2005;57:110R-7R

145. Wang L, Zhang Z, Wang Y, et al. Treatment of stroke with erythropoietin enhances neurogenesis and angiogenesis and improves neurological function in rats. Stroke. 2004;35:1732-7 
146. Gonzalez FF, Abel R, Almli CR, et al. Erythropoietin sustains cognitive function and brain volume after neonatal stroke. Dev Neurosci. 2009;31:403-11 147. Larpthaveesarp A, Georgevits M, Ferriero DM, Gonzalez FF. Delayed erythropoietin therapy improves histological and behavioral outcomes after transient neonatal stroke.

Neurobiol Dis. 2016;93:57-63

148. Brion LP, Bell EF, Raghuveer TS. Vitamin E supplementation for prevention of morbidity and mortality in preterm infants. Cochrane Database Syst Rev. 2003; 16(4): CD003665.

149. Mathew OP. Apnea of prematurity: pathogenesis and management strategies. J. Perinatol. 2011;31: 302-10

150. Rivkees SA, Wendler CC. Adverse and protective influences of adenosine on the newborn and embryo: implications for preterm white matter injury and embryo protection. Pediatr Res. 2011;69:271-8

151. Silva CG, Métin C, Fazeli W, et al. Adenosine receptor antagonists including caffeine alter fetal brain development in mice. Sci Transl Med. 2013;5:197ra104 152. Fleiss B, Tann CJ, Degos V, et al. Inflammation-induced sensitization of the brain in term infants. Dev Med Child Neurol. 2015;57 Suppl 3:17-28 153. Fazeli W, Zappettini S, Marguet SL, et al. Early-life exposure to caffeine affects the construction and activity of cortical networks in mice. Exp Neurol. 2017;295:88103

154. Vesoulis ZA, McPherson C, Neil JJ, et al. Early High-Dose Caffeine Increases Seizure Burden in Extremely Preterm Neonates: A Preliminary Study. J Caffeine Res. 2016;6:101-107 
155. Dix LML, van Bel F, Baerts W, Lemmers PMA. Effects of caffeine on the preterm brain: An observational study. Early Hum Dev. 2018;120:17-20

156. Hoecker C, Nelle M, Poeschl J, et al. Caffeine impairs cerebral and intestinal blood flow velocity in preterm infants. Pediatrics. 2002;109:784-7

157. Endesfelder S, Weichelt U, Schiller C, et al. Caffeine protects against anticonvulsantinduced impaired neurogenesis in the developing rat brain. Neurotox Res. $2018 ; 34: 173-87$

158. Wagenaar N, de Theije CGM, de Vries LS, et al. Promoting neuroregeneration after perinatal arterial ischemic stroke: neurotrophic factors and mesenchymal stem cells. Pediatr Res. 2018;83:372-84

159. Wei ZZ, Gu X, Ferdinand A, et al. Intranasal delivery of bone marrow mesenchymal stem cells improved neurovascular regeneration and rescued neuropsychiatric deficits after neonatal stroke in rats. Cell Transplant. 2015:1-40 160. Van Velthoven CTJ, Kavelaars A, van Bel F, et al. Mesenchymal stem cell transplantation changes the gene expression profile of the neonatal ischemic brain. Brain Behav Immun. 2011;25:1342-8

161. Stanne TM, Aberg ND, Nilsson S, et al. Low circulating acute brain-derived neurotrophic factor levels are associated with poor long-term functional outcome after ischemic stroke. Stroke. 2016;47: 1943-5

162. El Shimi MS, Hassanein SMA, Mohamed MH, et al. Predictive value of vascular endothelial growth factor in preterm neonates with intraventricular haemorrhage. $J$ Matern Fetal Neonatal Med 2012;25:1586-90

163. Koehne P, Hochhaus F, Felderhoff-Mueser U, et al. Vascular endothelial growth factor and erythropoietin concentrations in cerebrospinal fluid of children with hydrocephalus. Childs Nerv Syst. 2002;18:137-41 
164. Imam SS, Gad GI, Atef SH, Shawky MA. Cord blood brain derived neurotrophic factor: diagnostic and prognostic marker in fullterm newborns with perinatal asphyxia. Pak J Biol Sci. 2009;12:1498-504

165. Cotten CM, Murtha AP, Goldberg RN, et al. Feasibility of autologous cord blood cells for infants with hypoxic-ischemic encephalopathy. J Pediatr. 2014;164:973.e19.e1

166. Shimotake J, Derugin N, Wendland M, et al. Vascular endothelial growth factor receptor-2 inhibition promotes cell death and limits endothelial cell proliferation in a neonatal rodent model of stroke. Stroke. 2010;41:343-9

167. Kim ES, Ahn SY, Im GH, et al. Human umbilical cord blood-derived mesenchymal stem cell transplantation attenuates severe brain injury by permanent middle cerebral artery occlusion in newborn rats. Pediatr Res. 2012;72:277-84

168. Scafidi J, Hammond TR, Scafidi S, et al. Intranasal epidermal growth factor treatment rescues neonatal brain injury. Nature. 2014;506:230e234 ${ }^{* *}$ This study provides experimental evidence of a potential for epidermal growth factor receptor targeting as a strategy to treat white matter injury in preterm infants. 169. Wood TL, Loladze V, Altieri S, et al. Delayed IGF-1 administration rescues oligodendrocyte progenitors from glutamate-induced cell death and hypoxic-ischemic brain damage. Dev Neurosci. 2007;29:302e310

170. Zhong J, Zhao L, Du Y, et al. Delayed IGF-1 treatment reduced long-term hypoxia-ischemia- induced brain damage and improved behavior recovery of immature rats. Neurol Res. 2009;31:483e89

171. Oppliger B, Joerger-Messerli M, Mueller M, et al. Intranasal delivery of umbilical cordderived mesenchymal stem cells preserves myelination in perinatal brain damage. Stem Cells Dev. 2016; 25:1234e42 
172. Chen LX, Ma SM, Zhang P, et al. Neuroprotective effects of oligodendrocyte progenitor cell transplantation in premature rat brain following hypoxic-ischemic injury. PLoS One. 2015;10:e0115997

173. El-Dib M, Soul JS. The use of phenobarbital and other anti-seizure drugs in newborns. Semin Fetal Neonatal Med. 2017;22:321-327

174. Van Den Broek MPH, Groenendaal F, Toet MC, et al. Pharmacokinetics and clinical efficacy of phenobarbital in asphyxiated newborns treated with hypothermia: a thermopharmacological approach. Clin Pharmacokinet. 2012;51:671e9 175. Shellhaas $\mathrm{RA}, \mathrm{Ng} \mathrm{CM}$, Dillon $\mathrm{CH}$, et al. Population pharmacokinetics of phenobarbital in infants with neonatal encephalopathy treated with therapeutic hypothermia. Pediatr Crit Care Med. 2013;14: 194e202

176. Bittigau P, Sifringer M, Genz K, et al. Antiepileptic drugs and apoptotic neurodegeneration in the developing brain. Proc Natl Acad Sci U. S. A 2002;99:15089e94

177. Forcelli PA, Kim J, Kondratyev A, et al. Pattern of antiepileptic drug-induced cell death in limbic regions of the neonatal rat brain. Epilepsia. 2011;52:E207e11 178. Kaushal S, Tamer Z, Opoku F, et al. Anticonvulsant drug-induced cell death in the developing white matter of the rodent brain. Epilepsia. 2016;57:727e34 179. Hellstrom-Westas L, Boylan G, Agren J. Systematic review of neonatal seizure management strategies provides guidance on anti-epileptic treatment. Acta Paediatr. $2015 ; 104: 123 e 9$

180. Sarkar S, Barks JD, Bapuraj JR, et al. Does phenobarbital improve the effectiveness of therapeutic hypothermia in infants with hypoxic-ischemic encephalopathy? J Perinatol. 2012;32:15e20 
181. Young L, Berg M, Soll R. Prophylactic barbiturate use for the prevention of morbidity and mortality following perinatal asphyxia. Cochrane Database Syst Rev. 2016;5:CD001240

182. Strasser K, Lueckemann L, Kluever V, et al. Dose-dependent effects of levetiracetam after hypoxia and hypothermia in the neonatal mouse brain. Brain Res. 2016;1646:116-24

183. Arican P, Olgac Dundar N, Mete Atasever N, et al. Comparison of the neurocognitive outcomes in term infants treated with levetiracetam and phenobarbital monotherapy for neonatal clinical seizures. Seizure. 2020;80:71-7 184. Rennie JM, de Vries LS, Blennow M, et al. Characterisation of neonatal seizures and their treatment using continuous EEG monitoring: a multicentre experience. Arch Dis Child Fetal Neonatal Ed. 2019;104:F493-F501 185. Dzhala VI, Kuchibhotla KV, Glykys JC, et al. Progressive NKCC1-dependent neuronal chloride accumulation during neonatal seizures. J Neurosci. $2010 ; 30: 11745-61$

186. Nardou R, Yamamoto S, Chazal G, et al. Neuronal chloride accumulation and excitatory GABA underlie aggravation of neonatal epileptiform activities by phenobarbital. Brain. 2011;134:987-1002 187 Fitzgerald MP, Kessler SK, Abend NS. Early discontinuation of antiseizure medications in neonates with hypoxic-ischemic encephalopathy. Epilepsia. 2017;58:1047-1053

188. Guillet R, Kwon J. Seizure recurrence and developmental disabilities after neonatal seizures: outcomes are unrelated to use of phenobarbital prophylaxis. $J$ Child Neurol. 2007;22:389-95 
189. Guillet R, Kwon JM. Prophylactic phenobarbital administration after resolution of neonatal seizures: survey of current practice. Pediatrics. 2008;122:731-5

190. Dixon BJ, Reis C, Ho WM, et al. Neuroprotective Strategies after Neonatal Hypoxic Ischemic Encephalopathy. Int J Mol Sci. 2015;16:22368-401

191. Follet PL, Deng W, Dai W, et al. Glutamate receptor-mediated oligodendrocyte toxicity in periventricular leukomalacia: a protective role for topiramate. J Neurosci. $2004 ; 24: 4412 \mathrm{e} 20$

192. Schubert S, Brandl U, Brodhun M, et al. Neuroprotective effects of topiramate after hypoxia ischemia in newborn piglets. Brain Res 2005;1058:129e36 193. Liu Y, Barks JD, Xu G, Silverstein FS. Topiramate extends the therapeutic window for hypothermia mediated neuroprotection after stroke in neonatal rats. Stroke. 2004;35:1460e5

194. Filippi L, Fiorini P, Catarzi S, et al. Safety and efficacy of topiramate in neonates with hypoxic ischemic encephalopathy treated with hypothermia (NeoNATI): a feasibility study. J Matern Fetal Neonatal Med. 2018;31:973-980 195. Nuñez-Ramiro A, Benavente-Fernández I, Valverde E, et al; on behalf of the Hypotop Study

Group. Topiramate plus Cooling for Hypoxic-Ischemic Encephalopathy: A Randomized, Controlled, Multicenter, Double-Blinded Trial. Neonatology. 2019;116:76-84

196. Dzhala VI, Brumback AC, Staley KJ. Bumetanide enhances phenobarbital efficacy in a neonatal seizure model. Ann Neurol. 2008;63:222-35

197. Cleary RT, Sun H, Huynh T, et al. Bumetanide enhances phenobarbital efficacy in a rat model of hypoxic neonatal seizures. PLoS One. 2013;8:e57148 198. Pressler RM, Boylan GB, Marlow N, et al. Bumetanide for the treatment of 
seizures in newborn babies with hypoxic ischaemic encephalopathy (NEMO): an open-label, dose finding, and feasibility phase 1/2 trial. Lancet Neurol. 2015;14:46977

199. Brandt C, Seja P, Töllner K, et al. Bumepamine, a brain-permeant benzylamine derivative of bumetanide, does not inhibit NKCC1 but is more potent to enhance phenobarbital's anti-seizure efficacy. Neuropharmacology. 2018;143:186-204 200. Raol YH, Lapides DA, Keating JG, Brooks-Kayal AR, Cooper EC. A KCNQ channel opener for experimental neonatal seizures and status epilepticus. Ann Neurol. 2009;65:326-36

201. Sampath D, Shmueli D, White AM, Raol YH. Flupirtine effectively prevents development of acute neonatal seizures in an animal model of global hypoxia. Neurosci Lett. 2015;607:46-51

202. Kristensen LV, Sandager-Nielsen K, Hansen HH. Kv7 (KCNQ) channel openers induce hypothermia in the mouse. Neurosci Lett. 2011;488:178-82 203. Bouyssi-Kobar M, du Plessis AJ, McCarter R, et al. Third trimester brain growth in preterm infants compared with in utero healthy fetuses. Pediatrics. 2016; 138: e20161640

204. Lasky RE, Williams AL. Noise and light exposures for extremely low birth weight newborns during their stay in the neonatal intensive care unit. Pediatrics. 2009;123:540-6

205. Pineda RG, Neil J, Dierker D, et al. Alterations in brain structure and neurodevelopmental outcome in preterm infants hospitalized in different neonatal intensive care unit environments. J Pediatr. 2014;164:52-60.e2 
206. Schneider J, Duerden EG, Guo T, et al. Procedural pain and oral glucose in preterm neonates: brain development and sex-specific effects. Pain.

2018; $159: 515 \mathrm{e} 525$

207. Kamino D, Studholme C, Liu M, et al. Postnatal polyunsaturated fatty acids associated with larger preterm brain tissue volumes and better outcomes. Pediatr Res. 2018;83:93e101

208. Tam EW, Chau V, Barkovich AJ, et al. Early postnatal docosahexaenoic acid levels and improved preterm brain development. Pediatr Res. 2016;79: 723e730 209. Rose AL, Lombroso CT. A study of clinical, pathological, and electroencephalographic features in 137 full-term babies with a long-term follow-up. Pediatrics. 1970;45:404-25

210.Pressler RM. Neonatal seizures. In: From Channels to commissioning: a practical guide to epilepsy.

www.epilepsysociety.org.uk/sites/default/files/attachments/Chapter06Pressler2015.p df

211. Castro Conde JR, Hernández Borges AA, Doménech Martínez $E$, et al. Midazolam in neonatal seizures with no response to phenobarbital. Neurology. $2005 ; 64: 876-9$

212. van Leuven K, Groenendaal F, Toet MC, et al. Midazolam and amplitudeintegrated EEG in asphyxiated full-term neonates. Acta Paediatr. 2004;93:1221-7 213. Abend NS, Gutierrez-Colina AM, Monk HM, Dlugos DJ, Clancy RR. Levetiracetam for treatment of neonatal seizures. J Child Neurol. 2011;26:465-70 214. Weeke LC, Toet MC, van Rooij LG, et al. Lidocaine response rate in aEEGconfirmed neonatal seizures: Retrospective study of 413 full-term and preterm infants. Epilepsia. 2016;57:233-42 
215. Glass HC, Poulin C, Shevell MI. Topiramate for the treatment of neonatal seizures. Pediatr Neurol. 2011;44:439-42

216. Riesgo R, Winckler MI, Ohlweiler L, et al. Treatment of refractory neonatal seizures with topiramate. Neuropediatrics. 2012;43:353-6 


\begin{tabular}{|l|l|l|l|}
\hline DRUG & DOSING & CHOICE/LINE & REFERENCES \\
\hline Lorazepam & $0.05-0.1 \mathrm{mg} / \mathrm{kg}$ every $8-12$ hours & First/iv & 209,210 \\
\hline Diazepam & $0.2-0.5 \mathrm{mg} / \mathrm{kg}$ every 4-6 hours & First/iv & 209,210 \\
\hline Phenobarbital & $\begin{array}{l}15-20 \mathrm{mg} / \mathrm{kg} \text { every } 15-20 \mathrm{minutes} \\
\text { (maximum total dosing: } 40 \mathrm{mg} / \mathrm{kg})\end{array}$ & First/iv & 18 \\
\hline Phenyotin & $18-20 \mathrm{mg} / \mathrm{kg}$ & First/iv & 18 \\
\hline Midazolam & $\begin{array}{l}\text { Bolus: } 0.1-0.2 \mathrm{mg} / \mathrm{kg} ; \text { maintenance: } \\
0.05 \mathrm{mg} / \mathrm{kg} / \mathrm{h} \text { by continuous infusion, } \\
\text { (maximum speed: } 1 \mathrm{mg} / \mathrm{kg} / \mathrm{h})\end{array}$ & $\begin{array}{l}\text { Second- } \\
\text { (third)/iv }\end{array}$ & 211,212 \\
\hline Levetiracetam & Bolus: $10-60 \mathrm{mg} / \mathrm{kg}(30-60)$ & $\begin{array}{l}\text { Second- } \\
\text { (third)/iv }\end{array}$ & 213 \\
\hline Lidocaine & $2 \mathrm{mg} / \mathrm{kg}$ & Second-third/iv & 214 \\
\hline Topiramate & Maintenance: $3.5-10 \mathrm{mg} / \mathrm{kg}$ & $\begin{array}{l}\text { (Second)- } \\
\text { third/os }\end{array}$ & 215,216 \\
\hline
\end{tabular}

Table 1. Antiseizure medications for acute symptomatic neonatal seizures: dosing, order and route of administration, with reference to the pertinent literature. 


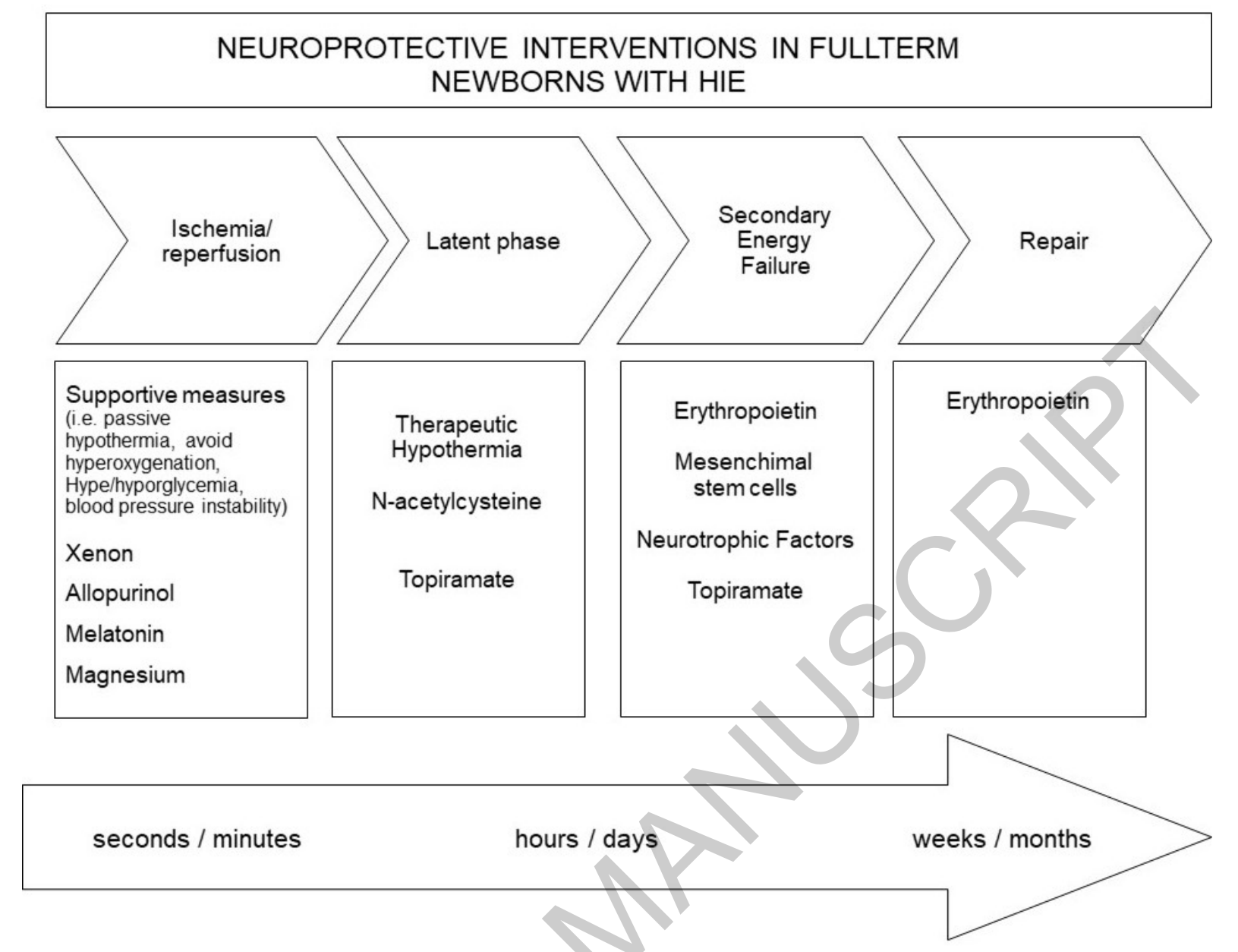

Figure 1 


\section{INTERVENTIONS FOR PRETERM NEWBORNS}

\begin{tabular}{|c|c|c|}
\hline $\begin{array}{c}\text { NEUROPROTECTIVE } \\
\text { (pre-OL death prevention) }\end{array}$ & $\begin{array}{c}\text { NEURORESTORATIVE } \\
\text { (prevention / amelioration of dysmaturation) }\end{array}$ \\
\cline { 2 - 4 }
\end{tabular}

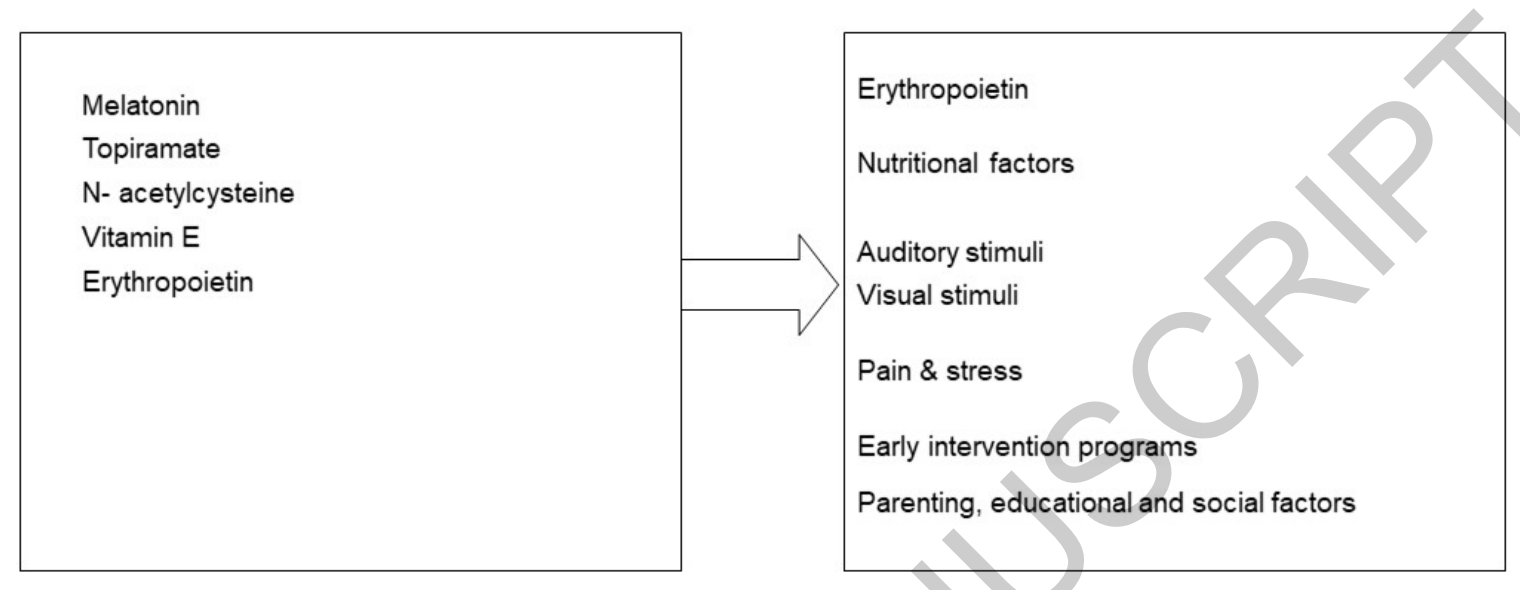

Figure 2 